\section{Tras la vitalidad de lo social. El uso de la etnografía en los procesos de extensión universitaria, una estrategia para la integralidad de funciones}

Patricia Fasano

Coordinadora del Área de Comunicación

Comunitaria de la Facultad de Ciencias

de la Educación.

Universidad Nacional de Entre Ríos, Argentina.

patrifasa@gmail.com
RECEPCIÓN: 24/04/19

ACEPTACIÓN FINAL: 30/05/19

\section{Resumen}

El artículo propone el uso de la etnografía como enfoque y método en el ámbito de la extensión universitaria, como estrategia posible para la producción de conocimiento y de concreción de la integralidad de funciones universitarias (de extensión, investigación y docencia) poniendo como centro al diálogo de saberes. Se basa, para ello, en la experiencia del Área de Comunicación Comunitaria de la Facultad de Ciencias de la Educación de la Universidad Nacional de Entre Ríos.

Palabras clave: etnografía, comprensión, comunicación comunitaria, registro etnográfico, diálogo.
Toward social life's vitality. Etnography in university extension processes, as an strategy for integrality of work

\section{Abstract}

The article proposes the use of ethnography as a view and a method to do university extension, as a possible strategy to product knowledge and to make the integrality of university functions (extension, research and teaching) placing dialogue between knowledges at the center place. To do that, It focuses on the Area of Communitary Communication's experience (in the context of the Faculty of Education Sciences in the University National of Entre Rios, Argentine).

Keywords: ethnography, comprehension, communitary comunication, ethnographic register, dialogue.
Cultura(s) en clave de extensión universitaria / Perspectivas
Perseguindo a vitalidade do social. A etnografia nos processos de extensão universitária, estratégia para a integralidade de funções

\section{Resumo}

O artigo propõe o uso da etnografia como enfoque e método no âmbito da extensão universitária como uma possível estratégia para a produção de conhecimento e concretização da integralidade das funções universitárias (extensão, pesquisa e docência), colocando no centro o diálogo de saberes. Para isso, baseiase na experiência da Área de Comunicação Comunitária da Faculdade de Ciências da Educação da Universidade Nacional de Entre Rios (Argentina).

Palavras-chave: etnografia, compreensão, comunicação comunitária, registro etnográfico, diálogo.

Para citación de este artículo: Fasano, P. (2019). Tras la vitalidad de lo social. El uso de la etnografía en los procesos de extensión universitaria, una estrategia para la integralidad de funciones. +E: Revista de Extensión Universitaria, 9(10), 3-16. doi: 10.14409/extension.v9i10.Ene-Jun.8286. 


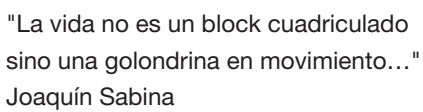

\section{Presentación}

Leí hace unos días una entrevista al Dr. Daniel Mato en un diario nacional en la cual el investigador de la Universidad de Tres de Febrero y de CONICET afirmaba que "la extensión universitaria enriquece la ciencia". ${ }^{1}$ Me conmovió la nota, no solo porque comparto el contenido de la expresión en todo su alcance (y del escrito en su conjunto) sino además porque se trata de uno de los postulados troncales del proyecto de trabajo del Área de Comunicación Comunitaria de la Facultad de Ciencias de la Educación de la Universidad Nacional de Entre Ríos, la que integro como coordinadora desde su creación en 2004.

Tomando en cuenta esa idea, me pareció propicio el espacio de esta revista para presentar un aspecto particular de nuestra perspectiva: concretamente, me refiero a la incorporación del enfoque etnográfico —clásicamente implementado en el ámbito de la investigación- a la extensión universitaria y lo que ello supone en términos de aporte a la integralidad de funciones.

Hablar de enfoque etnográfico implica, en principio, al menos dos cosas: a) adoptar para la consideración de lo social la mirada de la antropología, es decir, de lo social como construcción cultural y la necesidad de su desnaturalización; y b) considerar a la etnografía no solo un método de trabajo de campo sino una perspectiva (epistemológica) con relación a la producción de conocimiento, traducida en un método que atraviesa todo el proceso y no únicamente la etapa de trabajo de campo.

Para fundamentarlo, repasaré de manera breve los aportes específicos que la antropología —y más puntualmente la etnografía - hace a la investigación de lo social; describiré cómo incorporamos esa perspectiva en los procesos de intervención realizados desde la extensión universitaria por el Área de Comunicación Comunitaria, analogando la práctica extensionista a un proceso de investigación y colocando a la experiencia en el centro de la producción de conocimiento; reflexionaré sobre el uso que hacemos de las herramientas propias de la etnografía - como el diario de campo, el registro, la reflexividad y el extrañamiento-, para finalmente plantear, a través del análisis de algunos dilemas concretos, cómo efectuamos en concreto la integralidad de las funciones universitarias.

\section{El campo "habla" cuando es interrogado}

Allá por 2004, en los inicios del Área de Comunicación Comunitaria como motivadora de un proceso extensionista, se presentó una situación-problema que desde nuestra perspectiva resultaba paradójica: desde una radio comunitaria nos solicitaban apoyo para generar la participación del vecindario.

\footnotetext{
1) Me refiero a la entrevista realizada por Pablo Esteban (2019) "La extensión universitaria enriquece la ciencia" publicada en el diario Página/12 del 24 de abril. Esa entrevista está basada en el artículo de Daniel Mato (2018) "Repensar y transformar las universidades desde su articulación y compromiso con las sociedades de las que forman parte", publicado en esta misma revista.
} 
Esto nos resultaba, en términos teóricos, una contradicción: si el vecindario no participaba, ¿cuál era el fundamento "comunitario" de la radio? ¿Quería decir que podían existir radios "comunitarias" sin comunidades participando de ellas? La situación era interpretada por nosotras - desde nuestra formación académica - como una falta del ingrediente de la participación, entendido como condición fundamental para reconocer el carácter comunitario de las prácticas denominadas "de comunicación comunitaria". De modo que, al iniciar el vínculo con la experiencia, la propia formulación que los integrantes de la Comisión de la radio hacían del problema a partir del cual consideraban necesaria nuestra intervención ${ }^{2}$ nos llevaba a dudar de su pertinencia para (auto)encuadrarse en la definición. Allí iniciamos un proceso de acompañamiento de la experiencia que duró varios años.

Teniendo en cuenta que en las discusiones académicas y políticas sobre la comunicación comunitaria el asunto de la participación constituye uno de los más clásicos "talones de Aquiles" que suele hacer tambalear las experiencias comunitarias, la cuestión es: ¿nos quedamos con esa definición teórica - prescriptiva, deontológica- que nos lleva a clasificar a las prácticas de comunicación comunitaria en función de la pureza o impureza con que se presentan en ella atributos sustanciales por definición —tales como la participación de la comunidad, la inexistencia de fines de lucro y la gestión colectiva- o interponemos una perspectiva que habilite la aparición de otras posibles interpretaciones? El problema podría parecer una obviedad si no se le atraviesa una pregunta antropológica que nos conduzca a corrernos del sentido común naturalizado (en este caso, el sentido común académico naturalizado en nosotras, las observadoras): así, la paradoja puede ser interpretada como la expresión de un desencuentro entre sistemas interpretativos y teóricos (culturales) diferentes.

Esta fue solo la primera de una sucesión interminable de situaciones que se nos presentaron en esos años al realizar trabajos en terreno y que indefectiblemente nos situaban una y otra vez frente a un dilema: o bien los actores sociales se conducían de modos indisciplinados - con relación a las explicaciones brindadas en cada caso por las disciplinas de estudio de lo social— o bien nos declarábamos con necesidad de reconocer nuestra limitación para comprender el sentido de muchas de sus prácticas. Esas paradojas generalmente eran (y son) vividas como conflictos: la "falta de participación", la "falta de motivación", la "falta de recursos", la "falta de tiempo", etcétera.

Lo interesante es que, con el transcurso del tiempo, nos fuimos dando cuenta de que los conflictos nos remitían siempre a ese mismo dilema (teórico): la asunción de las propias perspectivas teóricas como deontologías acerca de cómo debería ser -y no cómo esefectivamente significada la vida social. Y esto nos fue conduciendo al corazón de la opción por una epistemología que hoy, a la luz de las lecturas recorridas desde entonces, llamaríamos dialógica. "Dialógica" por dos razones: porque señala un posicionamiento respecto de cómo entender la comunicación posible en todo encuentro (inter)cultural y porque ese posicionamiento nos posibilita enmarcarnos en las teorías sobre descolonialidad del poder y el saber, que proponen otras maneras de entender el lugar de la diferencia cultural en la construcción de conocimiento y de la universidad en dicho proceso. 
Trasladado al terreno de la producción de conocimiento, ese dilema implica o bien categorizar las prácticas de los actores sociales como resistiendo a las categorías de las ciencias sociales, o bien enfrentarnos a la necesidad de revisar nuestras categorizaciones para intentar conocer otros modos de interpretar las prácticas sociales.

En ese proceso epistemológico y político encontramos en el enfoque y el método etnográfico un aliado fundamental para articular las prácticas de extensión con las de investigación y docencia en el ámbito universitario.

\section{La etnografía como perspectiva sobre lo social}

La etnografía se delineó en el marco de los estudios antropológicos de lo social como su método específico para hacer trabajo de campo en los primeros años del siglo XX. Bronislaw Malinowski fue quien lo inscribió como tal en la historia de la disciplina y, a lo largo del siglo anterior y en lo que va del actual, lo que en principio consistió en una forma sistematizada de producir conocimiento antropológico — basada en la permanencia del propio investigador en el campo durante el tiempo necesario para inteligir sus especificidades-, a partir de importantes discusiones teóricas y filosóficas que no profundizaremos aquí se ha ido constituyendo como una posición ya no solo metodológica sino fundamentalmente epistemológica en relación con la producción de conocimiento (Nader, 2011; Ingold, 2008; Ghasarian, 2008).

Ahora bien, afirmar que es propia del conocimiento antropológico implica decir que su implementación es pertinente en el marco de un proceso investigativo cuyo objeto es la alteridad cultural (Krotz, 2010). En otras palabras, supone considerar a los grupos sociales como portadores de diferencias de índole cultural y, al mismo tiempo, que esas diferencias no tienen un carácter sustantivo sino que son producto de una determinada relación (definida como alteridad).

Siguiendo a Guber (2001), nos parece adecuado considerar la triple acepción de la etnografía: como enfoque, como método y como texto. Brevemente diremos que, como enfoque, se caracteriza por tener en el horizonte el conocimiento de los modos en que los propios actores sociales definen sus prácticas (lo que se denomina técnicamente "Perspectiva del Actor"), los cuales constituyen sistemas teóricos analogables a las teorías académicas o de autor con la única diferencia de que se trata de teorías vividas (Peirano, 2006). Como método, se caracteriza por la centralidad de un tipo de trabajo de campo a la vez extensivo en el tiempo e intensivo en cuanto al involucramiento que demanda del investigador, cuya principal herramienta de producción de información es su persona como un todo (mente/cuerpo/espíritu) a través de la observación participante como su técnica distintiva. Por último, como texto se trata de un género híbrido, tributario del ensayo por su pretensión explicativa y al mismo tiempo de la literatura por su arte para evocar en el lector el proceso de comprensión experimentado.

Lo que está en la base de toda la (triple) definición es un principio epistemológico que consiste en considerar a la experiencia como el lugar donde el conocimiento (antropológico) se produce (Turner, 1987). Desde la perspectiva del mundo académico occidental, el concepto de experiencia y su lugar en la producción del conocimiento reconoce sus orígenes en la filosofía fenomenológica (europea), una corriente que poco incidió en la definición de la 
epistemología predominante en el estudio científico de lo social (el positivismo). Sin embargo, se trata de un concepto largamente existente en las filosofías de los pueblos originarios: la experiencia como fuente, como lugar de conocimiento. Lo que hace la etnografía, tomando la propuesta teórica de la etnometodología (Wolf, 1979; Giddens, 1989), es traer este principio al seno de la antropología. A través de nuestras prácticas - de nuestra experiencia-, los agentes sociales creamos y recreamos el mundo social en el que vivimos mediante una permanente actividad interpretativa. La experiencia es el acto por el cual conocemos por medio de todo el cuerpo, incluyendo la mente, el intelecto y las emociones. Son/somos "teóricos prácticos". Tanto para vivir la vida cotidiana como para hacer ciencia social. (¿Por qué "hacer ciencia" sería una actividad diferente de otras que integran la vida cotidiana? La ciencia social es una forma de producción de conocimiento entre otras que es parte de la vida cotidiana. De ciertas vidas cotidianas: las nuestras.)

El reconocimiento de la experiencia como el lugar a través del cual ocurre la construcción de conocimiento supone establecer, desde el principio, unas reglas de juego que sientan las bases de una equiparación epistemológica entre distintos tipos de saberes, ya se trate de la ciencia o de los saberes populares. Esto no garantiza la "ecología de saberes" que demanda Boaventura de Sousa Santos para tratar de compensar la existencia de la línea abismal que implica la histórica visibilidad (y legitimidad) de la ciencia, la filosofía y la teología, por sobre "la invisibilidad de los conocimientos populares, laicos, plebeyos, campesinos o indígenas al otro lado de la línea" (2015:23), pero la predispone.

No siempre la etnografía supuso esto: por el contrario, en sus inicios evolucionistas y funcionalistas constituyó el brazo metodológico de una antropología funcional al colonialismo económico, cultural y, por lo tanto, necesariamente epistémico. Sin embargo, un siglo de discusiones al interior de la disciplina han hecho de su sofisticación una herramienta al servicio de procesos de conocimiento más inclusivos, y por ello políticamente más potentes. Y a veces queriéndolo y a veces no, cierto es que la etnografía contiene hoy los argumentos tanto teóricos como epistemológicos y metodológicos para concretar aquello que, ya no solo los precursores de la teoría de la decolonialidad representativos del "Sur" global más castigado y colonizado van construyendo, sino también autores europeos que vislumbran los límites y la crisis de las ciencias sociales actuales como, entre otros, Michel Maffesoli y Bruno Latour, pregonan cuando afirman que "quien compone la partitura es el cuerpo social, [entonces] hay que seguir su compás" (Maffesoli, 1997:19) y que "por motivos científicos, políticos e, incluso, morales, es crucial que los investigadores no definan por adelantado y en lugar de los actores de qué tipo de elementos constitutivos está hecho el mundo social" (Latour, 2005:67; cursivas en el texto original).

En conclusión, cuando comenzamos a pensar desde la etnografía es necesario, parafraseando a la antropóloga francesa Jeanne Favret-Saada, quien, en su antológico artículo Être affectée escrito a propósito de su investigación sobre la brujería, escribió: "permitirse ser afectado, (...) que uno arriesgue ver desintegrado el proyecto intelectual. Porque si este proyecto es omnipresente, nada sucede. Pero si algo sucede y aun así el proyecto intelectual permanece a flote, entonces la etnografía es posible" (2012:443; nuestra traducción). Solo de esa manera es posible que acontezca esa articulación teórica -entre las lógicas de quienes estudiamos y de quienes habitan el campo-que es propia de la labor interpretativa de la empresa etnográfica (Guber, 2013). 
Así, en lugar de categorizar los problemas de participación en la radio comunitaria como emergentes de una experiencia cuestionable conceptualmente ${ }^{3}$ por lo difícil de encuadrar en la categoría teórica de comunicación comunitaria, lo que hicimos fue comenzar a preguntarnos si no sucedería que lo social estuviese siendo más complejo que nuestras categorías para conceptualizarlo. ${ }^{4}$ Fue entonces cuando incorporamos la etnografía a las prácticas extensionistas y comenzamos el largo proceso (que aun continúa) de intentar comprender las perspectivas de los propios actores sobre las prácticas de comunicación comunitaria; dicho en otras palabras, el sentido de estas prácticas para ellos.

\section{La etnografía como estrategia}

La principal estrategia metodológica que implementamos es asimilar la práctica extensionista a un proceso permanente de investigación en el cual nuestras acciones en el terreno son concebidas como prácticas de participación en la vida social a través de las que, al mismo tiempo que intervenimos, observamos. Estos son los fundamentos más clásicos de la principal técnica de producción de información del proceso etnográfico: la observación participante, que va acompañada necesariamente del registro etnográfico como su principal herramienta.

La observación participante es la técnica que, desde que Malinowski (1975) patentizó las que constituirían las reglas del método a seguir para fundar un conocimiento científico del "otro" (Boivin, Rosatto y Arribas, 2011), se constituyó como característica del conocimiento antropológico. La técnica consiste en la inserción del antropólogo o de la antropóloga en la vida cotidiana de la población cuyas lógicas se procura comprender a través de la realización de una actividad que le lleva a participar de la misma como uno/a más, teniendo en cuenta que, como define Guber (2001), nunca se es un nativo más que funcionalmente y que, considerando que en tanto lo que se quiere comprender son teorías en estado práctico (Peirano, 2006), "si un juego se aprende jugando, una cultura se aprende viviéndola" (Guber, 2001:60). ${ }^{5}$

Esta manera de estar en el campo se implementa llevando un diario de campo integrado por registros que, en principio, consisten en anotaciones hechas in situ para fijar los detalles en la memoria y, a posteriori, se transforman en el contenido de lo que técnicamente se denomina "registro etnográfico", y que consiste en la elaboración de un texto en primera persona en el que se vuelca todo lo registrado, tanto en la exterioridad como en la interioridad de la persona del investigador: los detalles que llamaron la atención por distintas razones, las sensaciones experimentadas, las expresiones más o menos textuales de las personas, las situaciones vividas, en fin, todo (Guber, 1991; 2001). Si el texto final de una etnografía es el lugar donde se plasma la articulación de sistemas teóricos que ocurre a lo largo del

3) Y políticamente, pero no es ese el quid de esta cuestión.

4) Es justamente Maffesoli quien advierte que la propia palabra "concepto", en idioma alemán begriff, remite al francés "arañar", lo cual el autor relaciona con la operación del concepto, que "se impone, brutaliza, en vez de permitir el desarrollo natural de las cosas" (1997:22).

5) La asimilación de esta técnica como propia del trabajo antropológico, si bien extendida, no ha sido unámime. Entre otros, Claude Levi-Strauss, en Tristes Trópicos, criticó su incapacidad para posibilitar inferencias antropológicas de un mayor nivel de abstracción (Boivin, Rosatto y Arribas 2010). 
trabajo de campo, este proceso de objetivación comienza en el registro, ya que es allí donde, a través de la escritura, se objetiva — se traduce a un logos — la materia en principio caótica de la experiencia vivida.

\section{De la incomprensión a la comprensión}

Estando en terreno, el equipo extensionista se organiza para que al menos uno de sus integrantes registre. Los registros son, primero, notas de campo que luego, en un tiempo que generalmente cuadruplica al original, el o la autora convierte en un texto reflexivo; y con este adjetivo aludo al necesario ejercicio de la reflexividad, concepto que la etnografía ha tomado de la etnometodología para hacer consciente que en el trabajo de campo se encuentran al menos tres actividades interpretativas que se manifiestan fundamentalmente en el uso del lenguaje: la del investigador como académico, la del investigador como ciudadano y las de los actores sociales (Guber, 2001). ${ }^{6}$ A estas tres agregamos una cuarta: aquella que tiene lugar específicamente en ese trabajo de campo - y no en otro- a partir de las reglas implícitas que regulan esa interacción en particular (como ejemplo, apelo a la identificación de todo aquello que se puede/no se puede hacer/decir en cada situación concreta en terreno y que supone un modo puntual de dar una interpretación al vínculo de intervención/investigación).

El concepto de reflexividad propuesto por la etnometodología permite reconocer cuánto de indexicalidad y performatividad, ${ }^{7}$ de manera paralela, hay en el uso específico del lenguaje para dar un sentido — también específico- a cada situación social: A la vez, la incorporación del matiz propuesto por Bourdieu permite dar cuenta de una suerte de "control" u observación sistemática de la presencia de las respectivas subjetividades, especialmente la del investigador, en el proceso de producción de conocimiento (a la que el autor llama objetivación participante). ${ }^{8}$

"El primero en llegar es José (antes de las 17:00). Luego llegan, a su turno, José Luis y Enrique. Se ponen a tomar mates mientras nosotros terminamos con los adolescentes. En algún momento se suma Diego. (José trae su cuaderno de poemas; me da a leer uno y me dice que a ese lo escribió para la gente que compra [la revista] 'Barriletes' y que muchas veces lo mira con mala cara; ${ }^{9}$ el poema se dirige a los potenciales compradores y les cuenta sobre lo que es ser verdaderamente pobre; algunas de las cosas que recuerdo son: 'usted se preocupa por la humedad de su techo, pero no sabe lo que es no tener un lecho; no conoce el dolor de caminar durante horas con los dedos apretujados adentro de unos zapatos varios talles más chicos...', etcétera.)

6) Sobre este punto, y referido a nuestra experiencia, ver Schneider (2018).

7) La indexicalidad es la capacidad que tienen ciertos elementos del lenguaje para fijar el sentido de las frases en un aquí y un ahora. La performatividad tiene que ver con la capacidad del lenguaje de crear y recrear la vida social al mismo tiempo que se da cuenta de ella (Guber, 2001). Ambos conceptos tienen su significatividad en el ámbito de la etnometodología, en tanto esta corriente postula que todos los actores sociales somos "teóricos prácticos" y esa teoría no es otra cosa que el sentido común, siempre situado (Wolf, 1979).

8) Ver Bourdieu y Vacquant (1995).

9) José era vendedor de la revista Barriletes, perteneciente a la Asociación Civil Barriletes y consistente en un emprendimiento para generar trabajo para familias en situación de pobreza. 
Como a las 17:30 estamos listos para empezar, pero son muy pocos. Esperamos la llegada de Patricia y Delia. Como a las 17:45 decidimos empezar igual, teniendo en cuenta que va a hacer una hora que están esperando.

Comienza Enrique a decir que estuvieron 'reunidos' y charlaron sobre la posibilidad de empezar a hacer un programa los sábados para no tener que esperar a terminar los talleres y además para que 'la cosa no se vuelva a ir para cualquier lado'. Palabras más, palabras menos." (Fragmento del registro correspondiente al 23/10/2005 en los talleres realizados en la radio comunitaria Doña Munda).'

En el momento de la elaboración del registro -en el acto de evocación de la experiencia vivida y sus detalles a partir de las notas consignadas en el cuaderno-,${ }^{10}$ quien escribe va realizando una primera elaboración de esa situación en la que distintos sistemas interpretativos se han encontrado. ${ }^{11}$ Es allí cuando sorprende a veces la cantidad de detalles de lo vivido que aparecen al momento de volcar en un texto escrito lo evocado - descripción de ambientes, acciones, interacciones, sensaciones, olores, intuiciones, pensamientos, conjeturas, etc.-, lo evidencia cuánto registra la memoria de forma involuntaria cuando se está plenamente presente —con todos los sentidos—en la situación de campo. Luego, maravilla cómo se da un proceso a través del cual vamos poniendo en diálogo las categorías que traíamos con las que encontramos por primera vez.

"Al ratito Antonio, que estaba trabajando con José María y otro muchacho más ocupando la superficie de la mesa, se acercó a mí y me preguntó: '¿y usted por qué está acá sola?'. Le expliqué que lo que yo hacía era tomar notas sobre lo que se iba haciendo,' para poder mejorar el trabajo y corregir lo que hiciera falta. Me dijo entonces: 'Lo que tendrían que mejorar es la música. A mí no me gusta esa música, y además no se entiende nada... A mí lo que me gusta es...' (y volvió a enumerarme los mismos que nos había dicho antes). Además, me contó que él cantaba. Le dije que entonces podía cantar en la radio Chamuyo y me respondió rotundamente que no, que ¡ni loco!; 'acá toman todo para la chacota', me dijo. 'Por eso no se puede hacer nada como la gente; por eso no se puede tener una radio en serio, como en [las cárceles de] Las Flores y en Coronda, porque enseguida se van a poner a hablar en contra del Servicio Penitenciario, y ahí se termina todo... Son... — buscó la palabra adecuada tratando de no ser grosero— ¡boluditos! — dijo, dudando si la era-. ¡No aprovechan nada!...' En síntesis su argumento era que, si bien el Servicio Penitenciario es una porquería, lo cierto es que gracias al SP ellos tienen la posibilidad de aprender algo y salir con alguna herramienta más, si quieren y saben aprovecharlo. Entonces, es poco inteligente hablar mal públicamente del SP, porque se joden ellos solos... 'Y la verdad es que acá, a nadie le importa nada de nosotros. ¿Vos te creés que a alguien le interesa que vos te rehabilites y salgas lo antes posible? ¡No! ¿Y por qué no? Porque hay intereses económicos: mirá, yo soy preso federal, y el SP recibe mensualmente $\$ 13.000$ por mí. ¿Y vos te creés que se gastan esos 13.000 pesos en la comida de mierda que nos

10) O también en el grabador del teléfono celular o en el bloc de notas de este último o en la propia memoria a través de alguna técnica de memorización.

11) Al respecto, ver el capítulo VII "El registro de campo: primer análisis de datos" de Rosana Guber (1991) El salvaje metropolitano. 
dan? No. ¿Y adónde está esa plata? Entonces la cosa es clara...: cuantos más presos hay, más plata entra... Entonces, ¿vos te creés que me van a formar para que yo pueda salir y no volver nunca más? Por eso es que vos entrás acá siendo un chorro de cuarta y salís siendo un delincuente profesional... Si tenés 25 años de condena... ¿me querés decir si vas a salir mejor? Todo está hecho para que te quedes acá, o que salgas y vuelvas. Salís un tiempito y al tiempito estás adentro de nuevo, y eso es lo que le conviene a todo el mundo... Menos a nosotros... Pero acá nadie se pone a pensar — se señala la sien con el dedo índice de la mano- en lo que conviene... Y nadie se pone a pensar porque muchos muchachos son todavía pibes; muchos acá tienen 25 años pero juegan como si fueran pibes, y eso por qué? Porque no tuvieron infancia, porque les robaron la infancia; entonces están acá como si fueran mayores de edad, pero en realidad son pibes; lo de la edad es un verso, no tiene nada que ver... Porque mirá: ¿alguien se puso a pensar que los que venimos a este taller, fuera de acá nunca nos peleamos? ¿Que por qué los que venimos a este taller tenemos como una unidad fuera de acá, aunque somos de distintos pabellones...? Los que venimos a este taller afuera somos unidos, tenemos paz... Ponele vos que podemos tener un encuentro de palabras, que 'aquella profe me gusta a mí'... sin faltar el respeto, eh?... siempre con respeto... pero ponele que a mí me gusta una de las chicas y al otro también... pero nunca vamos a llegar a las manos por eso... y en otros talleres sí... Entonces, pensá un poquito -nuevamente se señala la sien con el dedo índice-: qué pasa acá? ¿Y entonces por qué no ponen más talleres como éste o ponen una radio de verdad, eh? Porque a nadie le importa... A todos les conviene que sigamos acá. Pero yo pienso en todas esas cosas, yo uso ésta - se toca otra vez la cabeza con el dedo índice -... Para mí la radio tiene que ser ponerle el micrófono a la persona para que cuente su vida, sus anécdotas; eso es lo lindo... que todos sepan... Con eso nomás ya tenés una noticia...'." (Fragmento del registro realizado el 09/09/16 en el taller que desarrolla el Equipo de Cárcel del ACC en la Unidad Penal №1 de Paraná. Los nombres son ficticios)

La expresión de Antonio, junto a la de otro y otro y otro, sumadas a nuestras observaciones y en el transcurso del tiempo, nos permiten comprender el contexto de significación específico que enmarca el sentido que tiene para los participantes lo que nosotros definimos como un taller de comunicación comunitaria en la cárcel.

Desde el punto de vista técnico, es importante la descripción minuciosa de los detalles, ya que es en ellos donde condensan los nudos de significatividad del encuentro (inter)cultural, facilitando por lo tanto la intelección propia y ajena de la acción a través de la comunicación textual. $Y$ en este sentido, el otro aspecto fundamental es escribir pensando en que otro $u$ otra lo va a leer -aunque en principio el registro no es una pieza comunicacional ideada para ser publicada-, ya que eso favorece el ejercicio de traducción a un logos cuyo primer destinatario es uno/a mismo/a.

Esto es parte de lo que en antropología se denomina "extrañamiento", proceso caracterizado por pivotear entre el distanciamiento y la aproximación (Lins Ribeiro, 2010) en virtud del juego dialéctico entre la vivencia (que aproxima) y la escritura (que distancia). Si en los comienzos de la constitución de la antropología como disciplina científica la distancia (geográfica, social) entre investigador y las sociedades "otras" era palpable objetivamente, con el acortamiento de las distancias se necesitó construir metodológicamente el distanciamiento, 
y esta operación se localizó en el extrañamiento entendido como procedimiento metodológico. Este procedimiento es el que la escritura del registro etnográfico permite materializar cuando es realizada de manera sistemática.

Al final del recorrido, nos encontramos con un proceso interpretativo cuya consecuencia más evidente es la aparición de nuevas categorías para entender lo social: las que son producto de la actividad interpretativa que el extensionista - ahora investigador- ha elaborado al "amasar" esa argamasa vivencial en la que diferentes categorías se han encontrado para dar cuenta de los múltiples sentidos de las prácticas.

\section{Lo social está vivo; las teorías, no siempre}

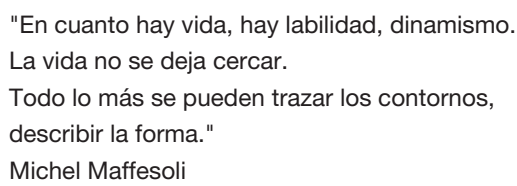

En nuestro caso, esos registros son utilizados con dos finalidades. La primera es la finalidad análoga a la sistematización, entendida como elemento necesario para la evaluación y redireccionamiento de las prácticas extensionistas: los registros son un sensible instrumento a través del cual el grupo puede ir monitoreando el transcurso del proyecto de extensión.

La segunda es la que nos interesa más a los fines de este artículo: posibilitar el proceso de comprensión del grupo al socializar no solo la experiencia vivida individualmente sino además el proceso reflexivo con relación a ella convertido en un proceso de conocimiento colectivo.

En el caso del Área de Comunicación Comunitaria, este proceso se continúa en innumerables reuniones en las cuales los conflictos emergidos en el trabajo en terreno y que nos generan dilemas son discutidos poniendo en juego las distintas perspectivas teóricas existentes y nuestras interpretaciones. Esto nos ha permitido, en los 15 años transcurridos desde su creación, hacer como grupo un proceso reflexivo que materializamos en distintos textos y espacios ${ }^{12}$ y que, más recientemente, plasmamos en un proyecto de investigación acreditado como tal en el sistema de proyectos de la Universidad Nacional de Entre Ríos. ${ }^{13}$ Y los diversos conflictos que aparecieron fueron encontrando otras formas de interpretación (teórica) que debieron ser traducidos en cada caso a creativos modos de resolución (práctica). A continuación, mencionaré algunos.

\section{Ejemplo 1: Cómo las mujeres conciben la participación}

Nos preocupaba el nulo o casi nulo ejercicio de la palabra por parte de muchas mujeres participantes de los talleres de género barriales. Algunas de ellas llegaban acompañadas por

12) Ponencias, artículos, el libro Construyendo comunidades... Reflexiones actuales sobre comunicación comunitaria (UNER/La Crujía, 2009), tesis de grado y posgrado, y la cátedra optativa Problemas contemporáneos de la comunicación: Procesos sociales e intervención, que forma parte de la Licenciatura en Comunicación Social (Universidad Nacional de Entre Ríos).

13) Se trató del PIDUNER ¿De qué hablamos cuando hablamos de comunicación comunitaria? Sistematización conceptual a partir de la experiencia del Área de Comunicación Comunitaria (FCEdu/UNER) 2015-2018. 
otra o por un grupito y "cuchicheaban" entre ellas. Cuando se proponía una consigna de trabajo la seguían obedientemente pero al momento de socializar lo que habían sentido, lo que pensaban, etc., permanecían en silencio. Esto dificultaba compartir grupalmente el proceso reflexivo en relación con las problemáticas de género que se iban trabajando y que culminarían en la elaboración de piezas comunicacionales colaborativas. Sin embargo, ni bien se interrumpía el tiempo del trabajo para compartir el mate y los bizcochitos, esas mujeres que en la instancia grupal no abrían la boca para expresarse se juntaban con quienes habían venido al encuentro y allí las veíamos hablar animadamente, inclusive de las temáticas propuestas desde el espacio de taller. Para eso habían venido, pensamos.

Esto motivó en el equipo de Género del Área de Comunicación Comunitaria, integrado entonces por dos docentes y varias estudiantes, un rico proceso de reflexión en torno a los conceptos de participación, ciudadanía comunicacional, taller e incluso sobre el rol de los comunicadores profesionales en el ámbito de la comunicación comunitaria, proceso para el cual los registros de los talleres constituyeron un insumo fundamental.

Esas mujeres, ¿participaban o no participaban? Observamos que la participación no siempre asumía la forma prevista y que ese "cuchicheo" en el momento del recreo era la forma posible que asumía la participación en esas personas para las cuales el uso público de la palabra constituía el más elemental de los derechos a la comunicación a conquistar y a ejercer. Ellas se sentían plenamente participantes de esos espacios en los cuales, desde nuestro punto de vista, no lográbamos que participaran.

Eso nos llevó a repensar los alcances del concepto de ciudadanía comunicacional, en el sentido de poder reconocer en él grados que incluyesen esas manifestaciones mínimas, necesarias para que se produjesen las otras, de aquella mujer cuyo primer paso en términos de la conquista de la ciudadanía comunicacional pasaba por poder asistir a un taller barrial $y$, en ese contexto, levantar la mirada para participar vivamente del clima grupal y aun, en el momento de los mates y bizcochitos, con sus más cercanas, compartir la expresión de su voz, oírla primero ella y hacerla oír luego entre sus vecinas más cercanas.

Todo eso nos llevó a reflexionar sobre el concepto de taller y la necesidad de incorporar el espacio del recreo al tiempo de trabajo: si en ese recreo las mujeres discutían las temáticas motivadas en el espacio-tiempo de trabajo, sería porque el proceso elaborativo del taller incluía ambos momentos y así debíamos pensarlo desde la planificación.

Por último, repensamos nuestro rol de comunicadoras profesionales en esos ámbitos y el lugar de la escucha como forma de comunicación. ${ }^{14}$ Estos aspectos, entre otros, forman parte de las conclusiones del proyecto de investigación, en el cual trabajamos detalladamente en el análisis de los registros de observación realizados con anterioridad.

\section{Ejemplo 2: La comunicación comunitaria desde la universidad}

En los talleres realizados con integrantes de organizaciones sociales observamos tres cuestiones. La primera fue que, por más que planificásemos instancias de taller participativas y dialógicas, se presentaba siempre una tensión entre la modalidad de trabajo que nosotras proponíamos y lo que los participantes nos solicitaban, directa o indirectamente: 
una clase, un dispositivo pedagógico en el cual la autoridad del saber se concentra en el docente, quien dicta la clase.

La segunda fue que siempre los procesos reflexivos de las instancias de taller se veían interrumpidos por la falta de tiempo, un tiempo que debía atender a la planificación y que debía llegar a producir lo prometido por el proyecto.

La tercera, que la propia forma del formulario del proyecto de extensión nos imponía la realización de un producto (final) que constituyese un indicador de su éxito, algo que no siempre surgía naturalmente del proceso grupal sino que debíamos inducirlo e incluso, a veces, forzarlo.

Si bien estas cuestiones se presentaron con más evidencia en los talleres con integrantes de organizaciones sociales, también se dieron en otras instancias de taller, como las cárceles y los talleres de comunicación comunitaria con productores y productoras rurales.

Estas observaciones, sistematizadas en múltiples registros, nos sirvieron para elaborar algunas hipótesis interpretativas en relación con las implicancias que tiene el desarrollo de proyectos de comunicación comunitaria desde la universidad y cómo eso impacta en la propia conceptualización de lo que entendemos — nosotros, los actores universitarios, y los demás actores sociales- por comunicación comunitaria. ${ }^{15}$

Sintéticamente diré que, respecto de la primera cuestión, lo que proponemos pensar es cuánto el hecho de representar en el trabajo extensionista a una institución con tanta legitimidad social en términos de producción -y portación- del saber técnico predispone la construcción de determinado tipo de vínculo pedagógico que, como todo vínculo, es producto de la colaboración de todas las partes. Y cuánto, por eso mismo, se torna necesario el despliegue de estrategias específicas para modificar esa predisposición en pos de la construcción de vínculos pedagógicos más dialógicos cuando está involucrada la universidad.

La segunda y la tercera de las cuestiones nos llevaron, necesariamente, a determinar cuánto el propio formato (técnico-administrativo, aunque producto de definiciones políticas) de los proyectos de extensión, incluido el diseño de su formulario de presentación, predispone a la realización de determinadas prácticas en detrimento de otras posibles. Y cuánto esto incide en la forma que asumen los proyectos de comunicación comunitaria propuestos desde las universidades y, por lo tanto y una vez más, la propia percepción de lo que va siendo la comunicación comunitaria tanto por parte de nosotras ${ }^{16}$ como de los demás actores sociales.

Este proceso nos demandó trabajar la investigación con una variedad de la etnografía denominada "autoetnografía", ya que aquí debimos interrogarnos a nosotras mismas y a nuestra experiencias particulares en tanto manifestación de una experiencia cultural (Denzin, 2013; Ellis, Adams \& Bochner, 2015), puesto que las cuestiones teóricas cuya tensión presenciamos y encarnamos en el terreno residían en parte en nosotras mismas como representantes de la institución universitaria.

Lo que pretendí poner en evidencia a través de los ejemplos mencionados es el modo en que puede producirse la inteligibilidad de las cuestiones sociales cuando se trabaja desde la perspectiva etnográfica en el ámbito de la extensión universitaria.

15) Esto también forma parte de las conclusiones del PIDUNER.

16) Me expreso en género femenino porque el equipo del ACC prioritariamente constituido por mujeres. 
El problema de participación de la radio comunitaria que planteamos al comienzo fue, junto a otro proceso desarrollado en otra organización barrial, nuestro bautismo en el trabajo desde esta perspectiva. Pasamos mucho tiempo sacando conclusiones sobre aquel espacio donde desarrollamos un proyecto de extensión que duró dos años y del cual aprendimos muchísimo: sobre la participación, sobre medios comunitarios, socialidad barrial, procesos de liderazgo, cultura popular, la relación entre la Iglesia Católica y el desarrollo de la comunicación comunitaria y popular en Argentina, etc. ${ }^{17}$ Asimismo, no hemos dejado de sacar conclusiones teóricas —en el marco de proyectos de investigación acreditados o fuera de ellos- en cuanto a los talleres que desde nuestros comienzos realizamos en las dos cárceles de Paraná y en ámbitos escolares y organizacionales diversos. ${ }^{18}$

Con este modo de trabajo alimentamos un proceso circular de aprendizaje y producción de conocimiento que comienza en el terreno, continúa en el box de investigación y luego en la cátedra de Problemas Contemporáneos de la Comunicación.

Lo que nos posibilita la incorporación de la etnografía al trabajo extensionista, en síntesis, es una estrategia para poder interrogar a la teoría desde las prácticas y a las prácticas desde la(s) teoría(s), para así visibilizar nuevos formas de concebir lo social provenientes de los saberes existentes en los distintos espacios sociales. A la vez, esto posibilita una sinergia que economiza esfuerzos y permite vivir de manera integrada el trabajo en el ámbito universitario. No es poco.

No somos pioneras; muchas experiencias por el estilo nos anteceden, algunas de ellas enmarcadas en lo que se denomina la "etnografía en colaboración" (Rappaport, 2007; Gandulfo, 2007; Dietz, 2012), cuya diferencia con el proceso que hemos descrito reside en que en este último caso el objetivo principal está puesto en la investigación y en el nuestro lo está en la intervención. Sin embargo, cuando se trabaja de manera sinérgica e integrada es difícil establecer rígidamente el límite entre una y otra. Y eso es lo que procuramos hacer, sin tener asegurado el éxito pero insistiendo en trazar un camino.

\section{Referencias bibliográficas}

Área de Comunicación Comunitaria (Comp.) (2009). Construyendo comunidades... Reflexiones actuales sobre comunicación comunitaria. Buenos Aires: La Crujía/UNER.

Boivin, M.; Rosatto, A. y Arribas, V. (2011). Constructores de otredad. Una introducción a la antropología social y cultural. Buenos Aires: Antropofagia.

Bourdieu, P.; Wacquant, L. (1995). Respuestas. Por una antropología reflexiva. México: Grijalbo. Denzin, N. (2013). Autoetnografía analítica o nuevo déjà vu. Astrolabio, (11).

17) Inclusive, a su análisis dediqué mi tesis de Doctorado en Antropología Social, titulada "Cambio de estilo. Comunicación, cultura popular y catolicismo en las radios comunitarias" (2011), actualmente en vías de publicación.

18) Algunas de estas reflexiones forman parte de la compilación Construyendo comunidades... (2009). Otras figuran en numerosas ponencias y artículos presentados por distintas integrantes del equipo extensionista. $Y$ otras se incluyen en las conclusiones del PIDUNER en cuya publicación nos encontramos trabajando actualmente. 
Dietz, G. (2012). Reflexividad y diálogo en etnografía colaborativa: el acompañamiento etnográfico de una institución educativa "intercultural" mexicana. Revista de Antropología Social, (21), 63-91.

Ellis, C.; Adams, T. \& Bochner, A. (2015). Autoetnografía: un panorama. Astrolabio, (14).

Favret-Saada, J. (2012). Being Affected. HAU: Journal of Ethnographic Theory, 2(1), 435-445.

Esteban, P. (2019). "La extensión universitaria enriquece la ciencia”. Página/12 (24/04/2019). Recuperado de: https://www.pagina12.com.ar/189390-la-extension-universitaria-enriquece-la-ciencia (consultado el 24 de abril de 2019)

Gandulfo, C. (2007). Entiendo pero no hablo. El guaraní "acorrentinado" en una escuela rural: usos y significaciones. Buenos Aires: IDES-Antropofagia.

Ghassarian, C. (2008). Por los caminos de la antropología reflexiva. En De la etnografía a la antropología reflexiva. Buenos Aires: Del Sol.

Giddens, A. (1989). Hermenéutica, Etnometodología y problemas del análisis interpretativo. Cuadernos de Antropología Social, (1). Buenos Aires.

Guber, R. (1991). El salvaje metropolitano. Buenos Aires: Legasa.

(2001). La etnografía: método, campo y reflexividad. Buenos Aires: Norma.

(2013). La articulación etnográfica. Descubrimiento y trabajo de campo en la investigación de Esther Hermitte. Buenos Aires: Biblos.

Ingold, T. (2008). Anthropology is not ethnography. En Proceedings of the British Academy, (154), 69-92. The British Academy.

Krotz, E. (2010). Alteridad y pregunta antropológica. En Boivin, M.; Rosato, A. y Arribas, V. Constructores de otredad. Una introducción a la antropología social y cultural. Buenos Aires: Antropofagia.

Latour, B. (2005). Reensamblar lo social. Una introducción a la teoría del actor-red. Buenos Aires: Manantial. Lins Ribeiro, G. (2011). Descotidianizar. Extrañamiento y conciencia práctica. Un ensayo sobre la perspectiva antropológica. En: Boivin, M.; Rosatto, A. y Arribas, V. Constructores de otredad. Una introducción a la antropología social y cultural. Buenos Aires: Antropofagia.

Maffesoli, M. (1997). Elogio de la razón sensible. Una visión intuitiva del mundo contemporáneo. BarcelonaBuenos Aires: Paidós.

Malinowski, B. (1975). Los argonautas del Pacífico Occidental. Barcelona: Península.

Nader, L. (2011). Ethnography as theory. HAU: Journal of Ethnographie Theory, 1(1), 211-219.

Mato, D. (2018). Repensar y transformar las universidades desde su articulación y compromiso con las sociedades de las que forman parte. +E Revista de Extensión Universitaria, 8(9), 38-52. doi: 10.14409/extension. v8i9.Jul-Dic.7837

Peirano, M. (2006). A teoría vivida e outros ensaios de Antropologia. Rio de Janeiro: Zahar.

Rappaport, J. (2007). Más allá de la escritura: la epistemología de la etnografía en colaboración. Revista colombiana de Antropología, 43, 197-229.

Sousa Santos, B. de (2015). Más allá del pensamiento abismal: de las líneas globales a una ecología de saberes. En Sousa Santos, B. de y Meneses, M.P. (Eds.). Epistemologías del Sur. Madrid: Akal.

Turner, V. (1987). The Antropology of Performance. New York: PAJ.

Wolf, M. (1979). Sociologías de la vida cotidiana. Cap. II: "Harold Garfinkel o La evidencia no se cuestiona". Barcelona: Cátedra. 